\title{
A New Species of Microporella (Bryozoa, Cheilostomata) from Alaska
}

\author{
Tsuyoshi Suwa $^{1 \dagger}$, Matthew H. Dick ${ }^{2}$ and Shunsuke F. Mawatari ${ }^{1 *}$ \\ ${ }^{1}$ Division of Biological Sciences, Graduate School of Science, \\ Hokkaido University, Sapporo 060, Japan \\ ${ }^{2}$ Department of Biology, Middlebury College, Middlebury, VT 05753, USA
}

\begin{abstract}
Microporella speciosa sp. nov. is described from Alaska, USA. The new species is characterized by the following combination of features: 1) semicircular orifice with slightly curved and faintly denticulate proximal edge having a straight, shallow groove, 2) two distal oral spines, 3) laterally directed avicularian rostrum with a broad, channeled tip, 4) open frontal pores, and 5) completely calcified basal walls. Opercula, avicularian mandibles, the ancestrula, and early ontogeny are also described.
\end{abstract}

\section{INTRODUCTION}

The genus Microporella (Bryozoa, Cheilostomata, Ascophora) contains species which have a remarkable general uniformity of appearance. Partly for this reason, taxonomists working in the North Pacific historically tended to report novel morphotypes as varieties of the type species of the genus, $M$. ciliata (Pallas) known from the North Atlantic. In addition (see Soule et al., 1995), Pacific species which were described as new were often later synonymized with $M$. ciliata by subsequent authors. Only recently have taxonomists begun to realize Microporella is considerably more speciose worldwide, and certainly in the North Pacific, than previously recognized. Dick and Ross (1988) reported four intertidally occurring species from the Kodiak Island vicinity, Alaska, three of which were described as new. In a recent comprehensive study, Soule et al. (1995) reported eight species, including four new to science, from southern California. Their work was followed by another intensive study by Suwa and Mawatari (1998) who reported seven species of Microporella, including five new species, from Hokkaido Island, Japan. These studies have expanded our understanding of diagnostic characters important in distinguishing species of Microporella.

In their Kodiak work, Dick and Ross (1988) reported only on species occurring intertidally. Subsequent to this work, one of us (MHD) recognized in his collection of Alaskan bryozoans specimens of an undescribed species of Microporella from subtidal depths in the Kodiak Island region, as well as from two other localities in western Alaska. This paper describes a new species based on this material.

\footnotetext{
* Corresponding author: Tel. +81-11-706-2750; FAX. +81-11-746-0862.

† Present address: Wakayama-ken Fisheries Experimental Station, 1551 Kushimoto, Kushimoto-cho, Nishimuro-gun, Wakayama-ken 649-35, Japan.
}

Specimens used for scanning electron microscopy were initially preserved only by drying. Specimens were cleaned with sodium hypochlorite solution, rinsed in tap-water and dried in air. Fixed specimens were cleaned with sodium hypochlorite solution, rinsed in tap-water and dried in air prior to their measurement under a binocular microscope. These dried materials were coated with gold by an ion sputter (JEOL: JFC$1100 \mathrm{E}$ ) and observed under a scanning electron microscope (JEOL: JSM-5400LV) at $15 \mathrm{kV}$ accelerating voltage. Mandibles and opercula were isolated by handling needles after the materials were decalcified in dilute $\mathrm{HCl}$. These isolated $\mathrm{cu}$ ticular parts were mounted with Amman's lactophenol on glass slides with coverslips and photographed under a light microscope.

The specimens described here are deposited in the Zoological Institute, Faculty of Science, Hokkaido University (ZIHU), Sapporo.

The following abbreviations are used for measurements: L, length; W, width; N, number; S. D., standard deviation; Nz, number of zooids.

\section{RESULTS}

Genus Microporella Hincks, 1877

Generic characters were emended by Suwa and Mawatari (1998).

Microporella speciosa sp. nov.

(Fig. 1A-K)

Material examined. HOLOTYPE: a mature colony of 8.0 $\mathrm{mm} \times 7.0 \mathrm{~mm}$; on the shell of Fusitriton oregonensis, subtidal, Narrow Strait, Kodiak Island vicinity, collected by M. H. Dick, 20 June 1981 (ZIHU-1165). PARATYPES: one immature colony on polychaete tube (ZIHU-1166) and one mature 

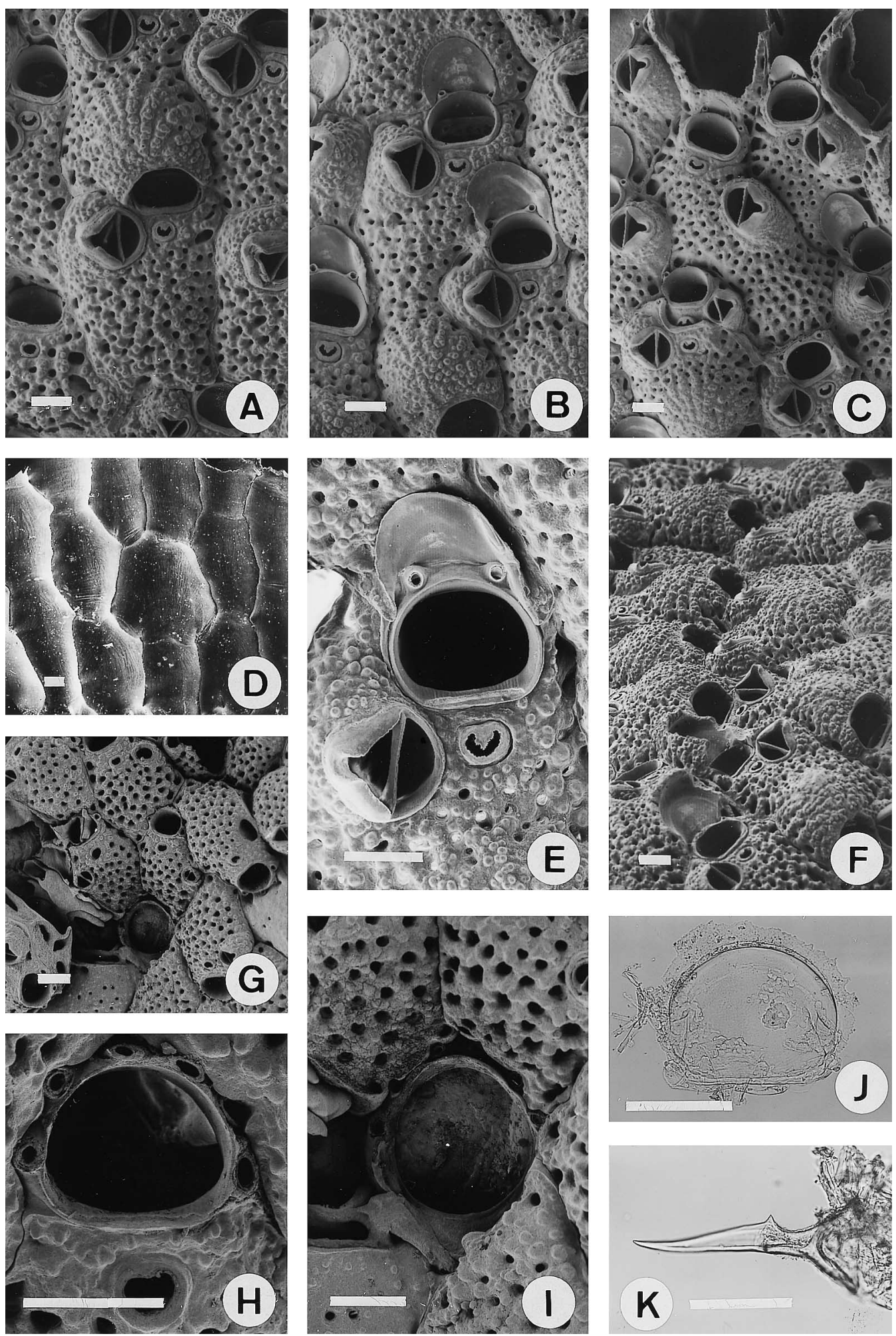

Fig. 1. Microporella speciosa sp. nov. A-F, J, K, Holotype (ZIHU-1165); G-I, Paratype (ZIHU-1166). (A) Brooding zooid. (B) Zooids with developing ovicells. (C) Peripheral part of a colony, showing zooids with conspicuous areolae. (D) Basal view of a colony, showing completely calcified basal walls. (E) Distal half of a zooid with developing ovicell. (F) Oblique view of zooids, showing ovicells with slightly flattened frontal wall. (G) An ancestrula and periancestrular zooids. (H) Distal half of a periancestrular zooid. (I) An ancestrula. (J) An operculum. (K) A mandible. Scale bars $=100 \mu \mathrm{m}$. 
(ovicellate) colony on barnacle fragment (ZIHU-1167), subtidal, Shuyak Strait, Kodiak archipelago, Alaska, collected by M. H. Dick, 26 July 1976. Additional material examined: one fragment of a young colony on drift algae, shore of Nanvak Bay, Bering Sea coast, Alaska, collected by M. H. Dick, Sept. 1972; 5 fragments of mature (ovicellate) colonies encrusting algae, Deer I., Cold Bay, Alaska, 7 m depth, collected by C. P. McRoy 17 Sept. 1970.

Etymology. The species name is from the Latin speciosus (beautiful).

Measurements. (ZIHU-1165. In mm except for $\mathrm{Nz}$ and N.)

$\begin{array}{lccccc} & & \text { Mean } & \text { Range } & \text { S. D. } & \text { Nz } \\ \text { Zooids without ovicells } & \text { L } & 0.70 & 0.54-0.91 & 0.098 & 10 \\ & \text { W } & 0.57 & 0.42-0.81 & 0.129 & 10 \\ \text { Primary orifice } & \text { L } & 0.15 & 0.14-0.17 & 0.013 & 10 \\ & \text { W } & 0.21 & 0.20-0.23 & 0.010 & 10 \\ \text { Ascopore } & \text { L } & 0.03 & 0.03-0.04 & 0.005 & 10 \\ & \text { W } & 0.06 & 0.04-0.07 & 0.008 & 10 \\ \text { Oral spine } & \text { N } & 2.50 & 2-3 & 0.500 & 10 \\ \text { Avicularian mandible } & \text { L } & 0.23 & 0.19-0.25 & 0.024 & 4 \\ \text { Ovicell } & \text { L } & 0.26 & 0.24-0.29 & 0.018 & 10 \\ & \text { W } & 0.36 & 0.35-0.37 & 0.007 & 10 \\ \text { Periancestrular zooid } & \text { L } & 0.60 & 0.59-0.61 & 0.010 & 2 \\ & \text { W } & 0.35 & 0.34-0.36 & 0.010 & 2 \\ \text { Oral spines } & \mathrm{N} & 6 & 6 & & 1\end{array}$

Description. Autozooids oval to hexagonal or somewhat irregular in shape (Fig. 1A, B), with conspicuous areolae in young stage (Fig. 1C). Basal wall complete, smooth (Fig. 1D). Frontal wall slightly convex, densely covered with nodules. Frontal pores small, round to oval, distributed evenly over the frontal; passing completely through the frontal wall. Primary orifice somewhat higher than a semicircle, curving inward to slightly curved proximal edge which has faintly denticulate inner rim and straight shallow groove (Fig. 1E). No distinct cardelles. Operculum of the same shape as the orifice except for the smooth proximal margin; proximally with 2 prominent muscular attachments (Fig. 1J). Oral spines usually 2, but 2 to 4 in some peripheral zooids, disposed along the distal border of the orifice. Ascopore close to the proximal border of orifice, separated from it by a distance equivalent to approximately one-third of the orifice length; crescentic, with a minutely toothed edge, raised on a thin oval to subreniform prominence (Fig. 1E). Frontal umbo lacking. Avicularia single, lateral to the ascopore. Avicularian chamber large, inflated; the surface densely tuberculate. Rostrum directed laterally, with a broadly channeled tip; the opening shortly triangular. Mandible with a lanceolate projection having paired hooks at the base (Fig. $1 \mathrm{~K})$.

Brooding zooids lack oral spines. Ovicell more or less spherical, but slightly flattened frontally (Fig. 1A, F), granular, delicately ribbed radially, perforated by several pores near the base.

Ancestrula (Fig. 1I) tatiform, with a large oval opesium surrounded by spines. Mural rim low, undulating, between the opesium and the spine row. Cryptocyst developed proximally, narrowing distally with a smooth surface. Basal wall lacking.

Periancestrular zooids (Fig. 1G, H) small, oval. Frontal wall sometimes bordered by a smooth, very narrow gymnocyst. Primary orifice with smooth proximal margin. Oral spines up to 5, disposed all around the distal curvature of the orifice.

Substrata. Microporella speciosa sp. nov. encrusts algal stems, calcareous surfaces among shell rubble, and the shells of living gastropods (Fusitriton oregonensis).

Remarks. Microporella speciosa sp. nov. resembles $M$. fimbricata Ryland and Hayward, 1992 in the following features: (1) nodular frontal surface; (2) crescentic ascopore with a minutely toothed edge, being separated from the proximal border of orifice by a distance equivalent to one-third of the orifice length; (3) primary orifice with a slightly curved and faintly denticulate proximal edge; (4) a straight shallow groove on the proximal rim of the primary orifice (this feature is apparent from fig. 26b in the original description of M. fimbricata, though it was not mentioned by the authors); and (5) unilateral avicularia with laterally directed rostrum. The new Alaskan species, however, differs from the Australian species $M$. fimbricata in having a shorter projection of the mandibles and narrower channel on the tip of rostum. Each of the other features of $M$. speciosa sp. nov. are separately found in other species of Microporella as follows: two distal oral spines are seen in M. neocribroides Dick and Ross, 1988; a similar mandible projection in M. pulchra Suwa and Mawatari, 1998; and a complete basal wall in M. formosa Suwa and Mawatari, 1998.

\section{DISCUSSION}

The known range of Microporella speciosa sp. nov. extends from the Gulf of Alaska to the southern Bering Sea. Four species of Microporella were found in an intensive intertidal study in the Kodiak Island region of the Gulf of Alaska (Dick and Ross, 1988), whereas M. speciosa was found only subtidally in that region and in western Alaska. This suggests that intensive investigations of bryozoans in nearshore and shelf regions throughout Alaska will disclose additional new species of Microporella. In general, the rate at which new species of Microporella have been accumulating in the literature dealing with North Pacific bryozoans has been very high. Dick and Ross (1988) reported three of four species (75\%) as new; Soule et al. (1995) reported four of eight species (50\%) as new; and Suwa and Mawatari (1998) reported five of seven species $(71 \%)$ as new. Furthermore, there is little overlap in nominal species between the three regions. Only $M$. californica is common to southern California and Alaska, and only $M$. neocribroides to Alaska and northern Japan. Even allowing the possibility of eventual synonymy among some of the nominal species involved, Microporella seems to have undergone a considerable radiation in the North Pacific, the extent of which has previously gone unrecognized. As further data become available, Microporella will provide fertile ground for studies of biogeography and speciation in this region. 


\section{REFERENCES}

Dick MH, Ross JRP (1988) Intertidal Bryozoa of the Kodiak Vicinity, Alaska. Center for Pacific Northwest Studies, Western Washington University, Bellingham, Occasional Paper No 23, pp 1-133

Ryland JS, Hayward PJ (1992) Bryozoa from Heron Islands, Great Barrier Reef. Memoirs Queensland Mus 32: 223-301

Soule DF, Soule JD, Chaney HW (1995) The Bryozoa. In "Taxonomic Atlas of the Benthic Fauna of the Santa Maria Basin and Western Santa Barbara Channel Vol 13" Ed by JA Blake, HW Chaney, PH Scott, AL Lissner, Santa Barbara Mus Nat Hist, Los Angeles, pp 1-344
Suwa T, Mawatari SF (1998) Revision of seven species of Microporella (Bryozoa, Cheilostomatida) from Hokkaido, Japan, using new taxonomic characters. Jour Nat Hist 32: 895-922

(Received November 12, 1997 / Accepted February 4, 1998) 